\title{
The influence of geology and season on macroinvertebrates in Belizean streams: implications for tropical bioassessment
}

\author{
Rachael Carrie ${ }^{1,2,4}$, Michael Dobson ${ }^{3,5}$, and Jos Barlow ${ }^{1,6}$ \\ ${ }^{1}$ Lancaster Environment Centre, Lancaster University, Lancashire LA1 4YQ UK \\ ${ }^{2}$ The Ya'axché Conservation Trust, Punta Gorda, Belize \\ ${ }^{3}$ The Freshwater Biological Association, Ambleside, Cumbria LA22 0LP UK
}

\begin{abstract}
Considerable attention has been paid to the potentially confounding effects of geological and seasonal variation on outputs from bioassessments in temperate streams, but our understanding about these influences is limited for many tropical systems. We explored variation in macroinvertebrate assemblage composition and the environmental characteristics of $3^{\text {rd }}$ - to $5^{\text {th }}$-order streams in a geologically heterogeneous tropical landscape in the wet and dry seasons. Study streams drained catchments with land cover ranging from predominantly forested to agricultural land, but data indicated that distinct water-chemistry and substratum conditions associated with predominantly calcareous and silicate geologies were key determinants of macroinvertebrate assemblage composition. Most notably, calcareous streams were characterized by a relatively abundant noninsect fauna, particularly a pachychilid gastropod snail. The association between geological variation and assemblage composition was apparent during both seasons, but significant temporal variation in compositional characteristics was detected only in calcareous streams, possibly because of limited statistical power to detect change at silicate sites, or the limited extent of our temporal data. We discuss the implications of our findings for tropical bioassessment programs. Our key findings suggest that geology can be an important determinant of macroinvertebrate assemblages in tropical streams and that geological heterogeneity may influence the scale of temporal response in characteristic macroinvertebrate assemblages.
\end{abstract}

Key words: biomonitoring, assemblage composition, temporal and spatial effects, Neotropics, Mesoamerica

In response to growing human pressure on the world's freshwater systems, bioassessment has become an integral component of stream management across the globe (Dolédec and Statzner 2010). The response of macroinvertebrate taxa to anthropogenic stress has been incorporated into policy and practice for water resource management in countries on every inhabited continent (e.g., ANZECC 2000, Council of the European Communities 2000, Dickens and Graham 2002, Barbour et al. 2006, Morse et al. 2007, Ministério do Meio Ambiente 2012). Accurate measurement of the effects of anthropogenic stress on macroinvertebrate assemblages requires a biologically meaningful reference against which potentially impaired assemblages can be compared (Hawkins et al. 2010). However, streams are influenced by numerous environmental factors that result in considerable natural het- erogeneity in macroinvertebrate composition (e.g., Vannote et al. 1980, Townsend and Hildrew 1994). Controlling for this variation is a prerequisite of bioassessment (Bailey et al. 2004).

Geology and season are 2 of the most important environmental factors producing heterogeneity in macroinvertebrate assemblage composition and bioassessment output in temperate streams (Munné and Prat 2011, Neff and Jackson 2011). Geological effects on macroinvertebrates have been related to variation in water chemistry (Olson 2012), food resources (Mosher and Findlay 2011), stream flow (Jin and Ward 2007), and water flow pathways (Barquín and Death 2006). Geology also influences habitat characteristics that are of direct significance to macroinvertebrate assemblages (Minshall 1984). Seasonal variation has been linked to life-history strategies and food availability

E-mail addresses: ${ }^{4}$ Present address: Institute of Science and Environment, University of Worcester, Henwick Grove, Worcester WR2 6AJ UK, r.carrie @worc.ac.uk; ${ }^{5}$ Present address: APEM Limited, The Technopole Centre, Edinburgh Technopole, Milton Bridge Nr Penicuik, Midlothian EH26 0PJ UK, m.dobson@apemltd.co.uk; ${ }^{6}$ jos.barlow@lancaster.ac.uk

DOI: 10.1086/681541. Received 30 April 2014; Accepted 13 January 2015; Published online 26 March 2015. Freshwater Science. 2015. 34(2):648-662. @ 2015 by The Society for Freshwater Science. 
(Johnson et al. 2012). Temperature and hydrology also can change with season and can be linked to geomorphological controls (Poff et al. 2006, Webb et al. 2008). Consequently, geological (e.g., alkalinity, proportion of calcareous bedrock) and seasonal (e.g., wet/dry, spring/autumn) variables often are incorporated in typological and site-specific predictive approaches to bioassessment that attempt to control for naturally occurring variation in temperate streams (e.g., Council of the European Communities 2000, Snelder et al. 2004).

Stream bioassessment is being implemented with increasing frequency in tropical developing countries (Jacobsen et al. 2008), where stratification to control for natural variation often focuses on factors related to longitudinal position or catchment size (e.g., altitude and stream order) (e.g., Baptista et al. 2007, Oliveira et al. 2011). With few exceptions (Moya et al. 2011, Dudgeon 2012), the potentially confounding effects of geology on macroinvertebrate distribution are seldom considered, despite the considerable geological variation that exists in many tropical catchments (Ramos-Escobedo and Vázquez 2001, Esselman et al. 2006). Furthermore, several investigators have examined macroinvertebrate seasonality in tropical streams, but a common pattern has not emerged (Jacobsen et al. 2008). Weak or absent seasonal signals have been observed in benthic and drift studies (Melo and Froehlich 2001, Ramírez and Pringle 2001), whereas distinct patterns in others have been attributed, in isolation and combination, to thermal, chemical, and hydrologic regimes (Flecker and Feifarek 1994, Jacobsen 1998, Ramírez et al. 2006, Rios-Touma et al. 2012).

In this context, we examined the relative importance of geology, season, and human disturbance on macroinvertebrate assemblage composition in streams in southern Belize. In this region, the macroinvertebrate fauna is poorly known and descriptions of environmental relationships have not been published. Nevertheless, we hypothesized that macroinvertebrate assemblages would be influenced by geology and season, as they are in temperate streams (Munné and Prat 2011, Neff and Jackson 2011), and we expected this influence to overwhelm influence related to catchment position and the relatively low levels of human disturbance that occur in southern Belize.

\section{METHODS}

\section{Study area}

We conducted our study in $\sim 2600 \mathrm{~km}^{2}$ of semideciduous upland and coastal-plain broadleaf rainforest and pine savanna known locally as the Maya Mountain Marine Corridor (MMMC). The MMMC is drained by tributaries of the Rio Grande, Golden Stream, Deep River, and Monkey River systems into the Port Honduras Marine Reserve in southern Belize (Fig. 1). The streams drain small-tomedium-sized catchments that can receive $>4000 \mathrm{~mm}$ of

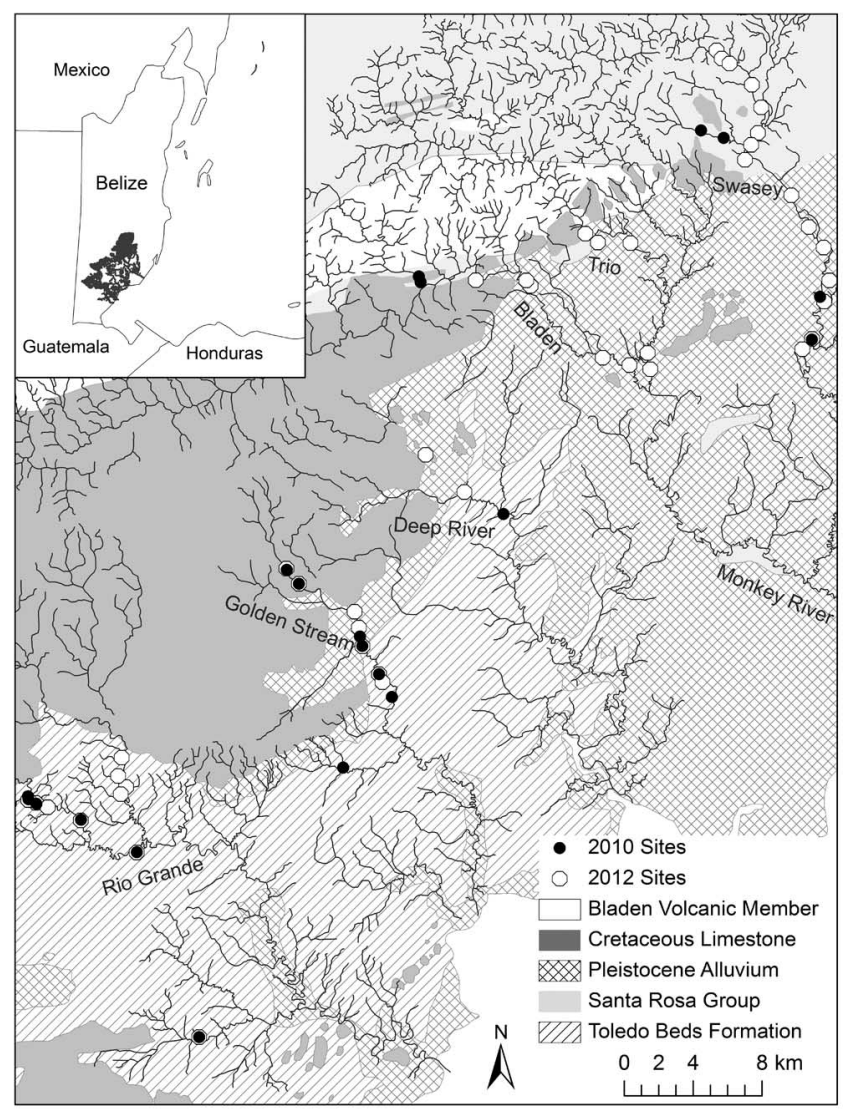

Figure 1. Sites sampled during 2010 and 2012 in southern Belize and their underlying geological characteristics. Rio Grande, Golden Stream, and Deep River are the southern catchments. The inset map shows the location of Belize in Central America and the locations of the studied catchments, which form the Maya Mountain Marine Corridor, in Belize.

precipitation per year, mostly during a distinct wet season (June-October). The region is geologically diverse (Fig. 1). The Monkey River system comprises 3 branches: the Swasey and Trio Rivers drain predominantly metamorphosed sediments of the Santa Rosa Group (SRG), and these rivers are affected by local intrusions of granite and contact metamorphism. The Bladen Branch is primarily influenced by the extrusive volcanic rocks of the Bladen Volcanic Member (BVM), and by extensive Cretaceous limestone before it flows, like the Swasey and Trio, through Pleistocene alluvium and deposits of calcareous sand and mud (Bateson and Hall 1977). Headwaters of the remaining systems drain Cretaceous limestone, which is characterized by karst topography typified by sinkholes, springs, caves, and underground streams, before reaching the coastal plain, which is composed of a series of shales, turbidites, calcareous and noncalcareous sandstones, conglomerates, and mudstones known as the Toledo Beds formation (Dixon 1956). The area is sparsely populated $\left(<7\right.$ people $/ \mathrm{km}^{2}$ ), with low levels of infrastructural or urban development. Subsistence 
farming, small-scale and commercial selective logging, cattle ranching, citrus and banana cultivation, and in-stream sand and gravel mining are the main sources of anthropogenic stress.

Our main assessment was undertaken using data collected between March and May (end dry season) and October and December (beginning dry season) in 2010. Twenty sites were randomly selected using RivEx+ software (version 6.9; RivEx, Southampton, UK) on stream sections below $125 \mathrm{~m}$ elevation in a sampling network stratified by 4 underlying broad surficial geological categories: 1 ) limestone $=$ Cretaceous limestones, 2 ) Toledo Beds $=$ the Toledo Beds formation, 3) volcanics $=$ the metamorphic and volcanic rocks of the Santa Rosa Group (SRG) and Bladen Volcanic Member (BVM), and 4) alluvium = Pleistocene alluvium deposits (Fig. 1, Table 1). We wanted to assess whether effects of geology could be detected regardless of human activity, so we stratified our sampling network by disturbance (forested/best available, disturbed).

Patterns observed resulted in an imbalance of sites among the most influential geologies and were potentially confounded by spatial effects (e.g., sites influenced predominantly by volcanics were in the Monkey River catchment). Therefore, we compared end-of-dry-season 2010 biological data with biological samples collected from 45 sites at the end of the dry season in 2012 (10 of which were the same as those visited in 2010 [highlighted in Table 1]) in a sampling network more evenly stratified by volcanic and limestone influence. Four of the 45 sites were influenced by a mixture of limestone and volcanic rocks, and 1 site on a tributary of the Monkey River system drained predominantly limestone in contrast to the remaining Monkey River sites which were influenced predominately by volcanic rocks (Fig. 1). The collection, laboratory, and nonmetric multidimensional scaling (NMDS) ordination methods described in the following sections were identical for samples taken during both survey years.

\section{Biological sampling and identification}

We sampled sites for macroinvertebrates during both seasons in 2010 and at the beginning of the dry season in 2012. Sampling was based on the Assessment System for the Ecological Quality of Streams and Rivers throughout Europe using Benthic Macroinvertebrates (AQEM) project methods (AQEM Consortium 2002) using a kick net (30- $\times 25-\mathrm{cm}$ frame, $500-\mu \mathrm{m}$ mesh) and manual sampling to enable a multihabitat approach. Multihabitat sampling is a standard way to deal with intrasite variability in habitat occurrence in bioassessment (e.g., Barbour et al. 2006), and we used it because of variability in habitats present among sites. We sampled 20 units $(30 \times 30 \mathrm{~cm})$ in microhabitats proportionally to their cover at each site. We defined microhabitats as a combination of substrate and flow type with coverage of $\geq 5 \%$ in a sampling reach $\sim 2 \times$ the average channel width. We established microhabitats based on manual mapping and visual estimation at each site. We fixed samples in the field with $10 \%$ neutral buffered formalin. In a departure from AQEM methods, and because few macroinvertebrate records exist for the study streams, we sorted specimens from all residue in the laboratory rather than from subsamples. We preserved specimens in $70 \%$ ethanol and used regional keys where available (Brown et al. 2009, Springer et al. 2010) and resources from North America (Merritt et al. 2008, Thorp and Covich 2009) for identification to family taxonomic level. We identified Ostracoda, Oligochaeta, Polychaeta, and Collembola to order and Brachyura to infraorder. When specimens could not be identified reliably to family because of damage or immaturity they were counted to order.

\section{Measurement of environmental variables}

We measured physicochemical variables during both seasons in 2010 simultaneously with benthic sampling. Triplicate measurements of stream-water temperature, dissolved $\mathrm{O}_{2}(\mathrm{DO}), \mathrm{pH}$, and electrical conductance (EC) were made in situ using hand-held probes (YSI 55; Yellow Springs Instruments, Yellow Springs, Ohio; Oakton PCSTestr 35; Eutech Instruments, Vernon Hills, Illinois). We measured $\mathrm{SiO}_{2}$ with the Hach DR890 following the silicomolybdate method (Hach Company, Loveland, Colorado).

We measured environmental variables at the beginning of the dry season only. Information about channel substratum, water depth and width, and riparian characteristics was collected following methods outlined by Peck et al. (2006) along 21 transects placed evenly to cover a distance equal to $40 \times$ the mean stream width. Current velocity was measured along 1 transect at $0.6 \times$ stream depth using the Valeport Braystoke flow meter (Valeport, Devon, UK) from which stream discharge was estimated following the cross-sectional-area procedure. We assessed stream condition with a version of the Stream Visual Assessment Protocol (SVAP) (Natural Resources Conservation Service 1998) adapted for Belizean streams (Esselman 2001). This method qualitatively ranks features describing the following physical attributes from 1 to 10 (channel condition, hydrologic alteration, riparian zone, water appearance, bank stability, nutrient enrichment, barriers to fish movement, in-stream fish cover, pools, insect/invertebrate cover, fishing pressure, riffle embeddedness, and manure presence). The average of the sum of these features provides an overall site score ranging from degraded (1) to reference condition (10). We recorded information about 11 types of disturbances (row-crop agriculture, subsistence agriculture, pasture, logging, laundry points, roads, mining, buildings, channel modifications, trash, and pipes) on both banks at each of the 20 transects following the methods of Peck et al. (2006) and summed these data to produce the human impact score (W1_Hall metric) as described by 


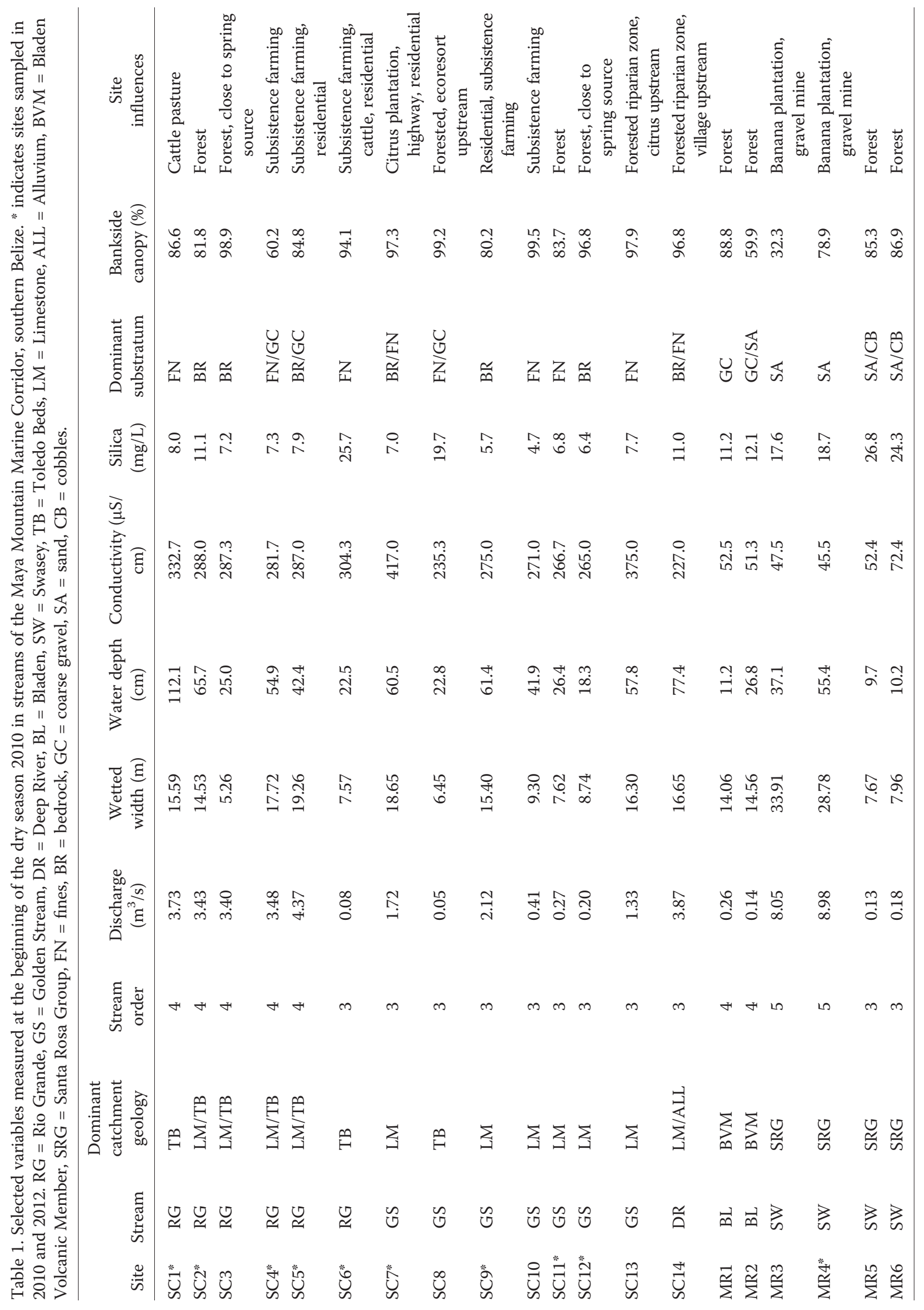


Kaufmann et al. (1999). We made adaptations to the disturbance categories outlined by Peck et al. (2006) to reflect the activities present in our study area (we replaced parks and lawns, which were not present, with subsistence farming, and pavements by laundry points). We weighted observations according to their proximity from the stream channel (on the bank or in the channel $[\times 1.5]$ ), within $10-\mathrm{m}$ of the bank and 10-m either side of the transect $(\times 1.0)$, and present beyond the $10-\mathrm{m}$ plot $(\times 0.667)$ (Kaufmann et al. 1999).

We obtained geographical, geological, and hydromorphological information with ArcGIS (version 9.2; Environmental Systems Research Institute, Redlands, California) and topographic maps $(1: 50,000)$. To compute the geological data, we calculated proportions of volcanics, limestone, Toledo Beds, and alluvium within the upstream subcatchment by intersecting geological information with coverage area. We used catchment geology rather than underlying geology to account for the cumulative effects on water chemistry and substrate material of upstream and underlying geology at a location, rather than localized effects related only to the geology underlying the sampled site.

\section{Statistical analysis}

Prior to analysis, we summarized environmental and biological data sets separately for each season and year. We explored patterns in environmental and biological data by using ordination techniques to identify sites with similar characteristics. We used principal components analysis (PCA) to summarize variation in the 27 environmental variables and to visualize the relationship between the 20 sites sampled during 2010. We used steepness of slope in the associated scree plot (assessed by presence of an 'elbow') and consideration of the variance explained to select the number of components to retain for further analysis. We used a varimax rotation to facilitate interpretation of the PCA components. Prior to PCA, we transformed data where necessary to reduce skewness because it can influence the PCA solution (Jolliffe 2002) (see Table 2 for transformations applied). We used NMDS based on Bray-Curtis similarity on $\log (x+1)$-transformed abundance data separately for the 2010 and 2012 biological data sets to summarize multidimensional patterns in macroinvertebrate assemblage structure and group samples by similarity. We retained 2-dimensional solutions because stress values were $\leq 0.2$ in all cases (Clarke and Warwick 2001). We used the indicator value method (IndVal) (Dufrêne and Legendre 1997) to identify taxa that discriminated among groups of sites. The indicator value of a taxon varies from 0 to 100, and it attains maximum value when all individuals of a taxon occur at all sites of a single group.

We used distance-based redundancy analysis (DistLM) (Anderson et al. 2008) to explore relationships among the rotated components and biological data. This analysis was undertaken only on the beginning-of-the-dry-season 2010 data set because the complete suite of environmental variables was not measured at the end of the dry season. In all cases, the $2^{\text {nd }}$-order corrected Akaike information criterion (AICc), a modification of the AIC specially designed for small numbers of samples $(<40)$, was used to rank combinations of principal components (PCs) (Burnham and Anderson 2002). First, marginal tests were done to assess the significance (from 9999 permutations) of the relationship between each principal component and the biological similarity matrix. Then the 'best' model-selection routine was used to identify parsimonious combinations of components that provided the lowest AICc value after adding the variables in a forward, backward, and stepwise fashion. Comparisons between models were based on differences in AICc values. Competing models fit the data similarly (a number of models had an AICc score within 2 points of the minimum AICc score), so we calculated an AICc weight as described by Burnham and Anderson (2002). This weight reflected the relative likelihood of each model being the best-fitting model among those considered, and allowed calculation of the relative importance of each component as the sum of model AICc weights over the subset of models within which each component occurred (Burnham and Anderson 2002). The higher the summed weights, the more important the component is. To avoid biasing relative importance values (i.e., by under or over representing any one component), we conducted this analysis over the entire model set (Burnham and Anderson 2002).

One-way permutational multivariate analysis of variance (PERMANOVA) tests were undertaken to compare seasonality in macroinvertebrate assemblages and water chemistry. We also assessed the temporal similarity of sites based on assemblage composition using the Procrustean randomization test PROTEST (Jackson 1995), to scale, rotate, dilate, and superimpose the 2010 end-of-dry-season NMDS ordination plot on the ordination produced for the 2010 beginning-of-the-dry-season data, before assessing the statistical fit using 1000 random permutations. Procrustean fitting is based on the least-squares criterion that minimizes the sum of the squared residuals $\left(\mathrm{m}^{2}\right)$ between the 2 configurations. The $m^{2}$ statistic provides a measure of concordance between the 2 ordinations. Assemblage composition varied among Monkey River system and southern catchment sites, so we also carried out 1-way PERMANOVA and PROTEST analyses separately for these groups of sites. When a significant seasonal effect was observed, we used IndVal to identify taxa discriminating between seasons.

The uneven sample size that resulted from the compositional patterns (Monkey River 6 sites, southern catchments: Rio Grande, Golden Stream, and Deep River 14 sites; see Table 1) could have contributed to the different sea- 
Table 2. Rotated principal component analysis (PCA) matrix detailing measured environmental variables (and transformations applied) at sites surveyed at the beginning of the dry season 2010 in streams of the Maya Mountain Marine Corridor, southern Belize. Variables weighted most strongly on each component are highlighted in bold. W1_Hall = human impact score. SVAP = Stream Visual Assessment Protocol.

\begin{tabular}{|c|c|c|c|c|c|}
\hline Variable & PC1 & $\mathrm{PC} 2$ & PC3 & PC4 & PC5 \\
\hline Eigenvalue & 8.04 & 6.13 & 3.77 & 2.44 & 1.58 \\
\hline$\%$ variation & 29.8 & 22.7 & 13.9 & 9.0 & 5.8 \\
\hline \multicolumn{6}{|l|}{ Variable (transformation) } \\
\hline \% limestone (arcsine) & 0.958 & -0.102 & 0.069 & -0.054 & 0.119 \\
\hline $\mathrm{SiO}_{2}$ & -0.843 & -0.284 & 0.219 & -0.186 & -0.068 \\
\hline \% volcanic (arcsine) & -0.841 & 0.075 & -0.497 & 0.099 & -0.039 \\
\hline Electrical conductivity & 0.809 & 0.031 & 0.501 & 0.010 & -0.087 \\
\hline$\%$ sand (arcsine) & -0.652 & 0.220 & -0.164 & -0.402 & 0.444 \\
\hline Temperature $(1 / \sqrt{ })$ & -0.572 & -0.275 & -0.189 & 0.400 & -0.427 \\
\hline \% bedrock (arcsine) & 0.562 & 0.199 & 0.531 & 0.541 & -0.027 \\
\hline Catchment size & -0.020 & 0.947 & 0.120 & -0.041 & 0.084 \\
\hline Discharge $\left(\log _{10}\right)$ & 0.203 & 0.935 & 0.030 & 0.131 & 0.035 \\
\hline Wetted width & -0.226 & 0.852 & -0.136 & -0.236 & 0.142 \\
\hline W1_Hall & -0.079 & 0.677 & 0.151 & -0.448 & -0.332 \\
\hline Depth & 0.361 & 0.676 & 0.375 & -0.062 & 0.105 \\
\hline SVAP & 0.405 & -0.528 & -0.485 & 0.347 & 0.106 \\
\hline \% bank canopy (arcsine) & 0.404 & -0.494 & 0.436 & 0.231 & 0.265 \\
\hline Turbidity & 0.013 & 0.056 & 0.852 & -0.141 & 0.180 \\
\hline Dissolved $\mathrm{O}_{2}$ & -0.336 & 0.217 & -0.800 & 0.093 & -0.128 \\
\hline Altitude & -0.027 & -0.458 & -0.773 & 0.088 & -0.001 \\
\hline \% Toledo beds (arcsine) & 0.211 & 0.059 & 0.716 & 0.058 & -0.608 \\
\hline$\%$ coarse gravel (arcsine) & -0.265 & -0.523 & -0.530 & -0.135 & -0.145 \\
\hline Substrate diameter $\left(\log _{10}\right)$ & 0.079 & -0.213 & -0.096 & 0.890 & -0.175 \\
\hline$\%$ boulders (arcsine) & -0.057 & -0.159 & -0.124 & 0.861 & -0.068 \\
\hline \% embeddedness (arcsine) & -0.239 & 0.047 & -0.310 & -0.823 & 0.173 \\
\hline \% fines (arcsine) & 0.352 & 0.280 & 0.369 & -0.710 & 0.117 \\
\hline \% fine gravel (arcsine) & 0.442 & -0.455 & 0.092 & -0.537 & -0.064 \\
\hline \% cobbles (arcsine) & -0.274 & -0.325 & -0.469 & 0.507 & -0.258 \\
\hline $\mathrm{pH}$ & 0.074 & 0.111 & -0.020 & 0.441 & 0.074 \\
\hline$\%$ alluvium (arcsine) & 0.138 & 0.076 & 0.325 & -0.153 & 0.807 \\
\hline
\end{tabular}

sonal signals among stream types, so we tested statistical power by resampling data from the southern catchment data set. We drew sample sizes of 6 and 12 fifty times (trials) and used a 1-way PERMANOVA to test for differences between seasons for each trial. The proportion of significant $(p<0.05)$ outcomes of the 50 trials for each sample size was the statistical power. We were unable to test the consistency of the seasonal signal among Monkey River and southern catchment sites (the interaction) using 2-way PERMANOVA tests for reasons of circularity (i.e., we could not generate and test a hypothesis using the same data set).

We undertook PCA, PROTEST, and IndVal tests with $\mathrm{R}$ freeware (version 2.15.2, R Project for Statistical Com- puting, Vienna, Austria). We ran all other analyses in PRIMER with the add-on package PERMANOVA+ (version 6; PRIMER-E Ltd., Ivybridge, UK).

\section{RESULTS}

\section{Environmental variation}

Visual inspection of the scree plot indicated that 5 PCs should be retained because an elbow was evident in the slope indicating the remaining PCs made a relatively small contribution to the variance explained in environmental characteristics (Fig. S1). Examination of the eigenvalues revealed that these 5 components accounted for $81.2 \%$ of variation in the environmental data, so they were retained for further analysis (Table 2). PC1 was mainly related to 
geological characteristics and associated variation in water chemistry and temperature. Increasing scores reflected a gradient from volcanic- to limestone-dominated catchments, low-to-high conductivity, and high-to-low $\mathrm{SiO}_{2}$ and temperature (Fig. 2A). Among riverbed features, bedrockand sand-dominated substratum also were weighted at opposite ends of this PC. PC2 was related to the longitudinal position of the site within the catchment, with positive scores representing a larger catchment, a wider and deeper channel, and greater discharge. Bankside canopy density and the W1_Hall and SVAP metrics also were loaded on PC2, highlighting the relationship between longitudinal position and human disturbance in the study streams (Fig. 2A). PC3 also reflected catchment position, with negative loadings representing higher-elevation sites and DO, whereas positive loadings indicated greater turbidity and the Toledo Beds geological group that characterized the coastal plains in the southern catchments (Table 2). PC4 described substratum characteristics and reflected a gradient in substratum size and embeddedness, with high positive loadings for \% bedrock, boulders, and cobbles present in the sampled reach and negative loadings for $\%$ fines and fine gravel. PC5 was mainly related to \% alluvium and the Toledo Beds formation in the catchment.

PC1 and PC2 accounted for $52.5 \%$ of variation in the original data and separated sites into 3 main groups ( $\mathrm{Ta}-$ ble 2 , Fig. 2B). The $1^{\text {st }}$ group consisted of 2 disturbed $5^{\text {th }}$-order sites that drained a large catchment area predominantly influenced by volcanic geology. The sites in this group were in the Monkey River system, had high $\mathrm{SiO}_{2}$, low conductivity, and a sandy substratum. Sites in the remaining 2 groups were all on $3^{\text {rd }}$ - and $4^{\text {th }}$-order streams. However, we found no clear pattern among sites to differentiate between these 2 stream-order categories. Rather, the $2^{\text {nd }}$ group consisted of 6 sites that had high $\mathrm{SiO}_{2}$. The wetted channel at these sites was narrower than the $1^{\text {st }}$ group of sites, shallower, and characterized by coarser substratum. This group included the remaining Monkey River catchment sites and 2 sites in the southern catchments. The twelve $3^{\text {rd }}$ - and $4^{\text {th }}$-order sites in the final group were characterized by high conductivity and low $\mathrm{SiO}_{2}$ and tended to be dominated by fines or a bedrock substratum. They varied in characteristics, such as catchment size, stream depth, and levels of disturbance, but all were on streams that drained limestone headwaters in the southern catchments.

\section{Variation in biological characteristics}

Environmental variation among sites generally was reflected by similar variation in biological characteristics: the assemblage composition at sites influenced by volcanic geology (those in the Monkey River catchment) was clearly distinguished from those more strongly influenced by limestone (those in the southern catchments) (Fig. 3A, B). Six taxa showed affinity for limestone-influenced southern catchment streams (Table 3). Four, including the most consistent indicator of this site grouping (Pachychilidae)
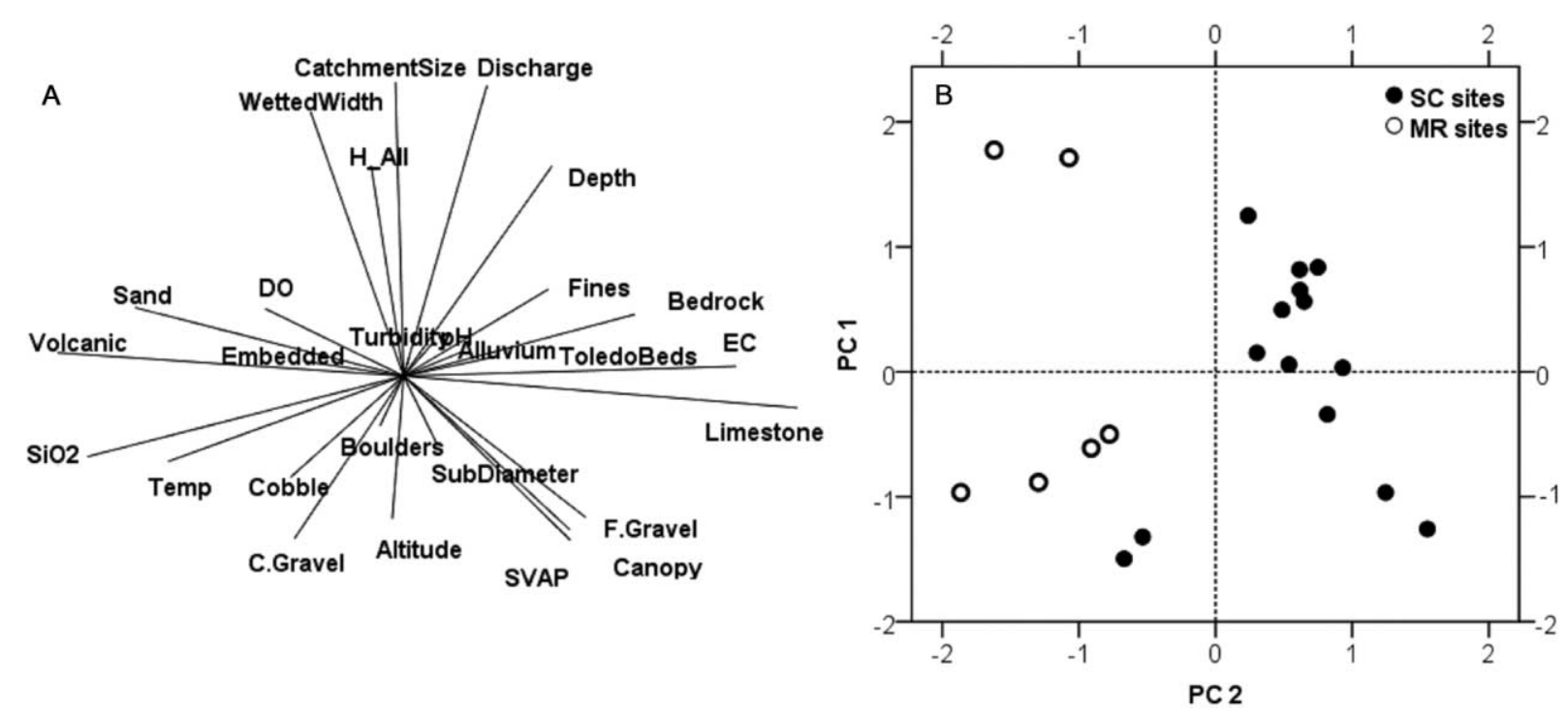

Figure 2. A.-Environmental variation among sites sampled at the end of dry season 2012 summarized in a principal components analysis (PCA) loading plot (PCs 1 and 2) for the 27 variables. Environmental variables are represented by lines that point in the direction of influence. B.-Distribution of sites on rotated components 1 and 2. H_All = human impact score, EC = electrical conductivity, $\mathrm{DO}=$ dissolved $\mathrm{O}_{2}$, C.Gravel $=$ coarse gravel, Temp $=$ temperature, SubDiameter $=$ substrate particle diameter, F.Gravel $=$ fine gravel, SVAP $=$ Stream Visual Assessment Protocol score. 

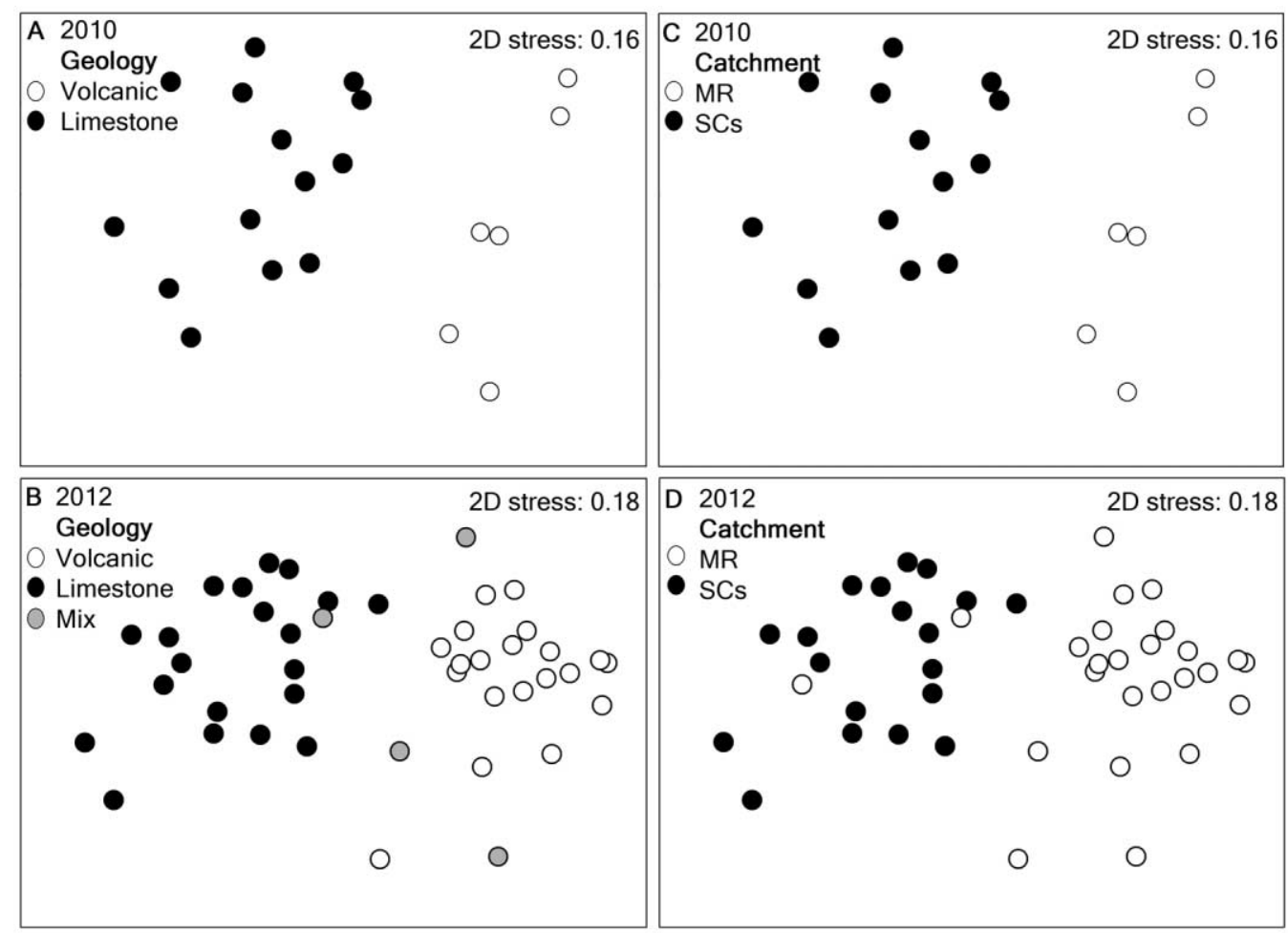

Figure 3. Nonmetric multidimensional scaling (NMDS) ordinations of the assemblage composition of macroinvertebrates sampled at sites influenced by volcanic and limestone geology (A, B) in the Monkey River (MR) and southern catchments (SCs) (C, D) of the Maya Mountain Marine Corridor in southern Belize at the beginning of the dry season 2010 (A, C) and the end of the dry season 2012 (B, D). Analysis based on $\log (x+1)$-transformed Bray-Curtis similarity. Mix = sites influenced by volcanic and limestone geology.

were noninsects. Fourteen taxa, all of which were insects, were indicators of sites influenced by volcanic geology (Tables 3, S1).

\section{Disentangling stream size and geology}

Because assemblage composition can vary with stream size, the inclusion of $5^{\text {th }}$-order sites in the Monkey River catchment may have confounded the patterns observed. However, similar patterns of distribution were evident among Monkey River and southern catchment streams when we removed the influence of $5^{\text {th }}$-order assemblages from our compositional data set (Fig. 3C, D, Fig. S2). Furthermore, Monkey River and southern catchment sites continued to be distinguished by similar insect and noninsect taxa (Table S2). Ten of the 14 taxa indicative of Monkey River streams when all sites were considered also were characteristic when $5^{\text {th }}$-order communities were removed, including taxa with adaptations to exploit conditions in larger streams (e.g., filter-feeding apparatus in Hydropsychidae, Simuliidae, and Philopotamidae) (Table S2). Removal of the $5^{\text {th }}$-order assemblages reduced the importance of Chironomidae, Leptohyphidae, Crambidae, and Staphylinidae, but Odontoceridae, Perlidae, Leptoceridae,
Calamoceratidae, Polycentropodidae, and Dryopidae remained or became characteristic of Monkey River streams.

\section{Macroinvertebrate-environment relationships}

DistLM analysis indicated that the 5 rotated components explained $53.6 \%$ of variation in the macroinvertebrate data. PCs 1,2 , and 3 were significantly related to variation in assemblage composition (PC1: $p<0.001$, PCs 2 and 3: $p<0.05$ ), and a model containing these 3 components was best able to explain the $53.6 \%$ of variation in macroinvertebrate data (Table 4). Eleven additional models containing information described by different combinations of the remaining components were also well supported $(\Delta i \leq 2)$. However, PC1 was the only PC included in all of them, and it was a strong explanatory variable (0.79) when relative variable importance weights were calculated across the entire model set (Fig. S3). These findings indicated that distinctive water-chemistry and substratum conditions related to volcanic and limestone geology are important drivers of macroinvertebrate assemblage composition in the studied streams, in addition to factors that are more commonly controlled for and assessed in biomonitoring studies (e.g., disturbance and catchment position, as indicated by PCs 2 and 3). 
Table 3. Mean ( $\pm 1 \mathrm{SE})$ abundance of families that were significant indicators of southern catchment (SC) and Monkey River (MR) sites. Families are ranked by the significance of their indicator value considering all sites.

\begin{tabular}{|c|c|c|c|c|}
\hline Family & Indicates & $\mathrm{SC}$ & MR & Indicator $p$ \\
\hline Pachychilidae & SC & $315.1 \pm 79.0$ & $2.2 \pm 1.5$ & 0.001 \\
\hline Helicopsychidae & $\mathrm{SC}$ & $9.8 \pm 3.2$ & $2.0 \pm 1.5$ & 0.008 \\
\hline Planariidae & $\mathrm{SC}$ & $12.7 \pm 3.1$ & $2.0 \pm 1.2$ & 0.010 \\
\hline Sphaeriidae & $\mathrm{SC}$ & $2.9 \pm 0.8$ & 0 & 0.012 \\
\hline Ecnomidae & $\mathrm{SC}$ & $1.9 \pm 0.5$ & 0 & 0.014 \\
\hline Palaemonidae & $\mathrm{SC}$ & $4.4 \pm 1.4$ & $0.3 \pm 0.2$ & 0.027 \\
\hline Simuliidae & MR & 0 & $72.7 \pm 56.6$ & 0.001 \\
\hline Hydroptilidae & MR & $1.4 \pm 0.7$ & $10.3 \pm 5.0$ & 0.001 \\
\hline Heptageniidae & MR & $1.6 \pm 0.5$ & $8.8 \pm 2.3$ & 0.002 \\
\hline Dolichopodidae & MR & $0.1 \pm 0.1$ & $1.5 \pm 0.4$ & 0.002 \\
\hline Chironomidae & MR & $80.7 \pm 14.7$ & $341.8 \pm 124.4$ & 0.005 \\
\hline Veliidae & MR & $3.8 \pm 1.8$ & $13.7 \pm 3.1$ & 0.007 \\
\hline Philopotamidae & MR & $0.9 \pm 0.4$ & $10.0 \pm 4.6$ & 0.008 \\
\hline Hydropsychidae & MR & $10.1 \pm 2.4$ & $56.3 \pm 18.7$ & 0.008 \\
\hline Calopterygidae & MR & $0.7 \pm 0.2$ & $6.5 \pm 1.9$ & 0.009 \\
\hline Corydalidae & MR & $1.1 \pm 0.4$ & $17.3 \pm 8.0$ & 0.011 \\
\hline Leptohyphidae & MR & $28.5 \pm 7.9$ & $155.5 \pm 44.1$ & 0.012 \\
\hline Psychodidae & MR & $0.1 \pm 0.1$ & $0.8 \pm 0.3$ & 0.012 \\
\hline Staphylinidae & MR & $0.3 \pm 0.2$ & $1.7 \pm 0.6$ & 0.016 \\
\hline Crambidae & MR & $2.8 \pm 1.3$ & $6.5 \pm 1.4$ & 0.037 \\
\hline
\end{tabular}

That variation in assemblage composition was strongly related to catchment geology was supported by our 2012 data set because NMDS analysis corroborated the geological patterns in assemblage composition observed in 2010. Regardless of disturbance, longitudinal position, and river catchment, sites heavily influenced by volcanic geology were compositionally similar relative to those more heavily influenced by limestone (Fig. 3A, B). Furthermore, assemblages influenced by limestone and volcanic geology were more variable and showed compositional similarities to assemblages characterizing both geological stream types (Fig. 3A, B). These results affirm that geology was a key driver of macroinvertebrate assemblage composition in the study streams and indicate that the influence of associated water chemistry and substratum conditions varied along a gradient of volcanic-limestone influence.

\section{Temporal variation}

Values for the suite of chemical variables measured during both seasons were significantly different when all sites were considered together (pseudo- $F=9.52, p=0.0001$ ), and when Monkey River (pseudo- $F=8.95, p=0.003$ ) and southern catchment sites (pseudo- $F=11.59, p=0.0001$ ) were considered separately. DO tended to be lower at the end of the dry season across all sites, and conductivity and $\mathrm{pH}$ tended to be higher.

Significant temporal variability was detected in the assemblage composition sampled at southern catchment sites (PERMANOVA, $F=1.76, p=0.027$ ). PROTEST analysis also confirmed an absence of concordance among sites distributed in ordination space (any similarity in ordination patterns was not statistically significant) $\left(m^{2}=0.38, p=\right.$ $0.25)$. However, assemblage composition showed only minor signs of seasonal differentiation when Monkey River sites were considered (PERMANOVA, $F=1.58, p=0.13$; Fig. S4). This result may reflect limited statistical power. If we assume the seasonal difference in each group of streams was of the same size, resampling 6 site subsets of the southern catchment data set attained a power of only 0.04 . However, we also failed to detect a seasonal effect when the entire data set (20 sites) was tested (PERMANOVA, $F=$ $1.51, p=0.10$ ), indicating that some variation may be present in the seasonal response among southern catchment and Monkey River assemblages (e.g., an effect in one stream type, but not the other).

Increasing the southern catchment subsample size to 12 improved statistical power but only to 0.50 , suggesting an inconsistent response to seasonal effects in the assemblage sampled from southern catchment streams. However, 
Table 4. Top-ranking models (those with $\Delta \leq 2$ ) of macroinvertebrate/environment associations with their relative weights $\left(\omega_{i}\right) \cdot$ AICc $=$ Akaike Information Criterion for small sample size, $\Delta i=$ difference between AICc- $i$ and the minimum AICc, PC $=$ principal component.

\begin{tabular}{lcccc}
\hline $\begin{array}{l}\text { Model rank } \\
\text { and included } \\
\text { components }\end{array}$ & AICc & $\Delta i$ & $\omega_{i}$ & Cumulative $\omega_{i}$ \\
\hline 1 PC1, 2, 3 & 131.91 & 0 & 0.13 & 0.13 \\
2 PC1, 3 & 131.99 & 0.08 & 0.13 & 0.26 \\
3 PC1 & 132.11 & 0.20 & 0.12 & 0.37 \\
4 PC1, 2 & 132.14 & 0.23 & 0.12 & 0.49 \\
5 PC1, 3, 5 & 133.24 & 1.33 & 0.07 & 0.56 \\
6 PC1, 2, 3, 5 & 133.25 & 1.34 & 0.07 & 0.63 \\
7 PC1, 5 & 133.26 & 1.35 & 0.07 & 0.69 \\
8 PC1, 3, 4 & 133.33 & 1.42 & 0.06 & 0.75 \\
9 PC1, 4 & 133.34 & 1.43 & 0.06 & 0.82 \\
10 PC1, 2, 3, 4 & 133.37 & 1.46 & 0.06 & 0.88 \\
11 PC1, 2, 5 & 133.40 & 1.49 & 0.06 & 0.94 \\
12 PC1, 2, 4 & 133.49 & 1.58 & 0.06 & 1.00 \\
\hline
\end{tabular}

IndVal analysis detected significant trends in the responses of certain noninsect taxa that characterized the southern catchment sites at the beginning of the dry season. Pachychilidae and Planariidae decreased in abundance at the end of the dry season, and certain insects (Leptohyphidae, Ceratopogonidae, Caenidae, and Elmidae) increased in relative importance (Table 5).

\section{DISCUSSION}

We are the first investigators to quantify macroinvertebrate-environment relationships in Belize (but see Boles 1998 for a descriptive assessment of an individual catchment), and ours is one of few tropical studies in which geology was considered as an important determinant of macroinvertebrate assemblage composition in the context of assessments of ecological integrity (for other studies see Moya et al. 2011, Dudgeon 2012). Overall, our hypothesis that geology and season would influence assemblage composition was upheld. Assemblages varied strongly along a gradient of volcanic-limestone influence. Environmental data indicated that this gradient was correlated with distinctive water-chemistry and substratum conditions. Moreover, although assemblage composition also varied in relation to human disturbance and longitudinal position, geological influence overwhelmed these effects. The patterns observed are particularly convincing because they were concordant in space and time (seasonally and annually). However, geology was not independent of river catchment in much of our study area (e.g., volcanic geology was mostly limited to the Monkey River catchment). We have presented limited data that suggests river catchment was not a key factor confounding the patterns observed (Fig. 3C, D), but our understanding may be complicated by this constraint.

Our results also suggest that season may differentially affect assemblages characterizing volcanic- and limestoneinfluenced streams. The consistency of seasonal response among geological stream types requires further investigation, but our results nevertheless contribute insight to the literature that reports considerable variation in patterns of macroinvertebrate assemblage seasonality in tropical streams (Melo and Froehlich 2001, Ramírez et al. 2006). Below we examine the effects of geological variation in water chemistry and substratum on assemblage composition and seasonal interactions before considering the implications of our findings for bioassessment programs in tropical streams.

\section{Factors influencing macroinvertebrate assemblages \\ Water chemistry Water-chemistry characteristics clearly} differed among volcanic- and limestone-influenced streams. The relative abundance of noninsects, particularly the pachychilid gastropod, was one of the most obvious differences in assemblage composition. A key variable explaining this dissimilarity was a water-conductivity gradient, presumably reflecting the dissolution of underlying rocks (e.g., limestone and Toledo Beds formation). These patterns are consistent with those observed by McKillop (1985) and Neff and Jackson (2011) who demonstrated that many mollusks show preference for solute-rich waters in calcareous Canadian streams. Moreover, they are biologically feasible because the distribution of certain invertebrates depends on the ionic composition of stream water regardless of additional environmental requirements (Huryn et al. 2008, Brown and Lydeard 2010, Covich 2010, Olson 2012).

Others working in the Monkey River catchment have measured $\mathrm{PO}_{4}{ }^{3-}$-enriched water in some minimally disturbed tributaries influenced by volcanic geology (specifically the SRG) (Esselman et al. 2006), and variation in nutrient availability could have contributed to the biological variation we observed. For example, dense stands of the macrophyte Marathrum oxycarpum (Podostemaceae; Burger 1983), which may provide habitat and refuge for invertebrates and enhance production, are present in some sections of streams draining the SRG geology (Shelley et al. 2002, Esselman et al. 2006). Macrophytes were present at some volcanic sites sampled during 2012. We did not deliberately exclude sites where macrophyte growth was present, but we did not encounter $M$. oxycarpum or other macrophytes at any site sampled during 2010. Therefore, the habitat and refuge they can provide were not directly 
Table 5. Mean ( $\pm 1 \mathrm{SE})$ abundance of families that were significant indicators of southern catchment sites at the beginning (Beg.) and end of the dry season in 2010. Beg. Dry = October-December, End Dry = March-May. Families are ranked by the significance of their indicator value.

\begin{tabular}{llccc}
\hline \multicolumn{1}{c}{ Family } & Indicates & Beg. Dry & End Dry & Indicator $p$ \\
\hline Planariidae & Beg. Dry & $12.7 \pm 3.1$ & $5.1 \pm 1.9$ & 0.020 \\
Pachychilidae & Beg. Dry & $315.1 \pm 79.0$ & $127.7 \pm 26.2$ & 0.021 \\
Gomphidae & Beg. Dry & $13.9 \pm 2.6$ & $7.0 \pm 1.7$ & 0.029 \\
Caenidae & End Dry & $1.5 \pm 0.7$ & $8.4 \pm 2.2$ & 0.006 \\
Ceratopogonidae & End Dry & $3.4 \pm 0.7$ & $8.9 \pm 1.9$ & 0.007 \\
Leptohyphidae & End Dry & $28.5 \pm 7.9$ & $113.4 \pm 42.9$ & 0.027 \\
Elmidae & End Dry & $70.1 \pm 18.9$ & $147.4 \pm 25.5$ & 0.027 \\
\hline
\end{tabular}

related to the variation in assemblage composition we observed in the 2010 data set. However, leaf litter from instream macrophytes can contribute to stream nutrient budgets (Newman 1991), and others have indicated that invertebrate characteristics (e.g., growth rate and turnover) may be influenced by high-P food resources in other naturally enriched tropical streams (Ramírez and Pringle 2006). Further studies designed specifically to explore the relative influence of chemical characteristics associated with the SRG geology on macroinvertebrate assemblages would be a worthwhile endeavor in this study area.

Substratum Substratum characteristics also varied between limestone and volcanic sites. Increased sand and cobble at volcanic sites were paralleled by variation in the abundance of insect taxa including Corydalidae and Leptohyphidae (Table 3), which often inhabit cobble and gravel riffles and sand substratum that characterized most Monkey River streams (e.g., Goulart and Callisto 2005, Cover and Resh 2008). Bedrock dominated the limestoneinfluenced streams in the southern catchments (Table 1). These sites were characterized by taxa, including Pachychilidae and Planariidae, that have adaptions to cling to rock surfaces. Variation in the macroinvertebrate assemblage in relation to substratum characteristics was expected because geomorphological heterogeneity influences macroinvertebrate assemblage structure (Erman and Erman 1984). Attributes of substratum size, mobility, and complexity in particular, have been correlated with insect richness and diversity elsewhere (Rabeni and Minshall 1977, Vinson and Hawkins 1998). Relationships between substratum complexity and flow heterogeneity also can be reflected in assemblage composition, and the insect assemblage indicative of Monkey River sites possessed anatomical or behavioral adaptations to exploit a range of flow conditions. For example, Simuliidae, Hydropsychidae, and Heptageniidae, which were characteristic of these sites
(Table 2), are adapted to live on exposed rock surfaces to exploit fast currents for food or $\mathrm{O}_{2}$, whereas the Philopotamidae often are found attached to surfaces exposed to lower flows in erosional habitats (Merritt and Wallace 2009).

Season Streams in tropical zones have much lower annual variation in temperature than those in temperate regions, but distinct wet/dry seasonality can produce dynamic discharge regimes that alternately disrupt and amplify flows and hydrological connectivity. Therefore, the compositional variation we observed among seasons was expected, especially because seasonal changes in macroinvertebrate assemblages have been strongly linked to rainfall in other tropical streams (Flecker and Feifarek 1994, Jacobsen 1998, Ramírez et al. 2006). However, the relative magnitude of change observed in southern catchment streams was unexpected when compared with the minor differences among seasons at Monkey River sites, particularly because chemical variables varied consistently among geological stream types. The lack of a seasonal signal in Monkey River samples could have been a statistical rather than ecological effect, reflecting the limited power that 6 samples provided to test seasonality in these streams, but the lack of significant effect when all 20 samples were tested gives some indication that the strength of response may differ among stream types.

One plausible explanation for the seasonal variation in compositional data may be related to geomorphological controls on flow characteristics that are specific to streams in the southern catchments. Riffles were sampled at all survey sites. However, at the beginning of the dry season, average water levels tended to be shallower in Monkey River than in southern catchment streams (Table 1). The latter were characterized by moderately deep bedrock glides and taxa with preferences for depositional habitats, including Helicopsychidae, Ecnomidae, 
and Planariidae (Vaughn 1987, Dudgeon 1999) (Table 3). An increase in the importance of riffle taxa, like Elmidae and Leptohyphidae, and families, such as Caenidae and Ceratopogonidae, that prefer lentic conditions (Nolte et al. 1997, Borkent et al. 2009) (Table 5), at southern catchment sites at the end of the dry season suggests that decreasing water levels produced pools and exposed shallow gravel deposits that were previously submerged, thereby increasing the availability of riffle and pool habitat simultaneously. Despite the increase at the end of the dry season in records of some insect taxa more characteristic of Monkey River streams than at southern-catchment sites, the assemblages sampled from each system remained distinct (Fig. S4), indicating that site-specific changes in substratum characteristics may be less important than broad-scale geological variation in water chemistry.

Some of the seasonal variation in southern catchment streams also might be explained by life-history strategies of certain of the taxa that characterized these sites at the beginning of the dry season. Pachychilidae, the taxa most indicative of this stream type, was significantly more abundant at the beginning of the dry season when numerous juveniles were observed. Anecdotal evidence of seasonality in Pachychilidae exists for other sites in the study area (Cochran 2008). Furthermore, seasonal patterns of abundance have been observed in Asian Pachychilidae, which are thought to vary production seasonally to reduce larval mortality (Dudgeon 1982). Pachychilidae also are collected for food by villagers in our study area when streams are accessible during the dry season. Life-cycle strategies to avoid scouring flows may account for the significant reduction in numbers of Gomphidae at the end of the dry season (Table 5). Some members of this family fly at the start of the rainy season in the Neotropics (Paulson 2004) and emerge as early as March in Belize (Boomsma and Dunkle 1996).

Our study was of limited duration, and we did not consider the interannual variation that others have found to be significant (Flecker and Feifarek 1994), but our results provide some support to the notion that season can have varying effects on tropical macroinvertebrate assemblages (Jacobsen et al. 2008), even in neighboring streams, and provide interesting insight about the role geological controls may play in determining effect. Ultimately, however, more temporal and spatial replication is required to clarify the nature of the interaction among season and stream type.

\section{Implications for bioassessment of tropical streams}

The potential for geology and season to confound bioassessment outputs in temperate streams is widely recognized (Sanchez-Montoya et al. 2007, Munné and Prat 2011, Johnson et al. 2012). We have shown that geological variation also occurs in macroinvertebrate assemblages in tropical streams. Furthermore, we cautiously suggest that seasonal effects may vary differentially among geological stream types, but this observation is based on limited data. Controlling for natural variation is a prerequisite of bioassessment, not only so that reference assemblage types can be identified, but also to ensure that metrics selected for assessing impairment do not vary in their performance among reference assemblages (e.g., Mykrä et al. 2004). How the compositional variation observed will translate to scores obtained from biotic metrics that are robust for use in tropical streams remains to be seen. However, differences in the relative importance of taxa among Monkey River and southern catchment streams, including Odontoceridae, Perlidae, Leptoceridae, Calamoceratidae, Heptageniidae, and Ecnomidae (Table 3, Table S2), that are generally considered indicators of good stream condition (MINAE-S 2007) suggest the sensitivity of bioassessment efforts may be reduced if they fail to incorporate geological heterogeneity, not least because of the potential for temporal effects.

Measures to control for geological effects on reference assemblages are incorporated in both predictive site-specific and typological bioassessment programs in temperate regions (e.g., Council of the European Communities 2000, Davy-Bowker et al. 2008). The broad geological groupings we observed correspond with the calcareous and silicate classifications that inform typological stratification of bioassessment in many streams (Barbour et al. 1995, Omernik 1995, Council of the European Communities 2000, Snelder et al. 2004). This finding suggests that large-scale typologies could provide a biologically meaningful starting point for stratifying bioassessment in geologically simple tropical catchments where additional sources of variation like catchment size and longitudinal position can be controlled by relatively straightforward hierarchical classifications (e.g., Esselman et al. 2005). However, the data we have presented from streams influenced by both silicate and calcareous geologies suggest that large-scale typologies may be too coarse to partition compositional variation effectively in geologically complex tropical streams. We predict that future compositional analysis undertaken in catchments influenced by complex geologies will reveal patterns that support arguments advocating site-specific approaches (e.g., Wright 2000, Linke et al. 2005, Van Sickle 2008) that can better account for continuous variation in environmental features and biological assemblages (DavyBowker et al. 2006, Sanchez-Montoya et al. 2007, Hawkins et al. 2010).

\section{ACKNOWLEDGEMENTS}

This research was funded by NERC-ESRC grant ES/F013035/1, the kind support of the Rufford Small Grants Foundation (grants 11376-1\&2), and the Freshwater Biological Association Hugh Cary Gilson Memorial Award for 2012. This work was made possible by the support of the Ya'axché Conservation Trust, and 
in particular Devina Bol, Anignazio Makin, Octavio Cal, Pastor Ayala, and Abelino Zuniga who provided invaluable knowledge and assistance in the field and laboratory. We also thank Lee McLoughlin and Marchillio Ack for logistical support. We gratefully acknowledge the Belize Fisheries Department, Belize Forest Department, and Belize Agricultural Health Authority for supporting this research and permitting the study and export of specimens. We are grateful to Percival Cho for geographical information system assistance, Dan Polhemus, Monika Springer, David Baumgardner, and Ian Wallace for assistance with taxonomy and Peter Esselman, John Murphy, Alonso Ramírez, and the anonymous referees whose comments have contributed greatly to improving this manuscript.

\section{LITERATURE CITED}

Anderson, M. J., R. N. Gorley, and K. R. Clarke. 2008. PERMANOVA+ for PRIMER: guide to software and statistical methods. PRIMER-E Ltd., Plymouth, UK.

ANZECC (Australian and New Zealand Environment and Conservation Council). 2000. Australian and New Zealand guidelines for fresh and marine water quality Australia. Australian and New Zealand Environment and Conservation Council, Agriculture and Resource Management Council of Australia and New Zealand, Canberra, Australia. (Available from: http:// www.environment.gov.au/water/publications/quality/australian -and-new-zealand-guidelines-fresh-marine-water-quality-volume-1)

AQEM Consortium. 2002. Manual for the application of the AQEM method. A comprehensive method to assess European streams using benthic macroinvertebrates, developed for the purpose of the Water Framework Directive. AQEM Consortium, Essen, Germany. (Available from: http://www.aqem.de /mains/products.php)

Bailey, R. C., R. H. Norris, and T. B. Reynoldson. 2004. Bioassessment of freshwater ecosystems: using the reference condition approach, Kluwer Academic Publishers, Norwell, Massachusetts.

Baptista, D. F., D. F. Buss, M. Egler, A. Giovanelli, M. P. Silveira, and J. L. Nessimian. 2007. A multimetric index based on benthic macroinvertebrates for evaluation of Atlantic Forest streams at Rio de Janeiro State, Brazil. Hydrobiologia 575:83-94.

Barbour, M. T., J. B. Stribling, and J. R. Karr. 1995. Multimetric approach for establishing biocriteria and measuring biological condition. Pages 63-77 in: W. S. Davis and T. P. Simon (editors). Biological assessment and criteria. Tools for water resource planning and decision making. Lewis Publishers, Boca Raton, Florida.

Barbour, M. T., J. B. Stribling, and P. F. M. Verdonschot. 2006. The multihabitat approach of USEPA's rapid bioassessment protocols: benthic macroinvertebrates. Limnética 25:839-850.

Barquín, J., and R. G. Death. 2006. Spatial patterns of macroinvertebrate diversity in New Zealand springbrooks and rhithral streams. Journal of the North American Benthological Society $25: 768-786$.

Bateson, J. H., and I. H. S. Hall. 1977. The geology of the Maya Mountains, Belize. HMSO, London, UK.

Boles, E. 1998. Developing a community-based rapid watershed assessment protocol focusing on the Sibun River in Belize as a case study. PhD Dissertation, Jackson State University, Jackson, USA.

Boomsma, T., and S. W. Dunkle. 1996. Odonata of Belize. Odonatalogica 25:17-29.

Borkent, A., G. R. Spinelli, and W. L. J. Grogan. 2009. Ceratopogonidae (biting midges, Purrujas). Pages 407-436 in B. V. Brown, A. Borkent, J. M. Cumming, D. M. Wood, N. E. Woodley, and M. A. Zumbado (editors). Manual of Central American Diptera. NRC Research Press, Ottawa, Ontario.

Brown, B. V., A. Borkent, J. M. Cumming, D. M. Wood, N. E. Woodley, and M. A. Zumbado. 2009. Manual of Central American Diptera. Volume 1. NRC Research Press, Ottawa, Ontario.

Brown, K. M., and C. Lydeard. 2010. Mollusca: Gastropoda. Pages 277-307 in J. H. Thorp and A. P. Covich (editors). Ecology and classification of North American freshwater invertebrates. Academic Press, London, UK.

Burger, W. 1983. Flora Costaricensis: Podostemaceae. Fieldiana: Botany, New Series 13:1-8.

Burnham, K. P., and D. R. Anderson. 2002. Model selection and multimodel inference: a practical information theoretic approach. Springer, New York.

Clarke, K. R., and R. M. Warwick. 2001. Change in marine communities: an approach to statistical analysis and interpretation. Plymouth Marine Laboratory, Plymouth, UK.

Cochran, J. L. 2008. Diet, habitat and ecomorphology of cichlids in the upper Bladen River, Belize. MS Thesis, Texas A\&M University, Lubbock, Texas.

Council of the European Communities. 2000. Directive 2000/ $60 /$ EC. Establishing a framework for community action in the field of water policy. European Commission, Luxembourg.

Cover, M. R., and V. H. Resh. 2008. Global diversity of dobsonflies, fishflies, and alderflies (Megaloptera; Insecta) and spongillaflies, nevrorthids, and osmylids (Neuroptera; Insecta) in freshwater. Hydrobiologia 595:409-417.

Covich, A. 2010. Winning the biodiversity arms race among freshwater gastropods: competition and coexistence through shell variability and predator avoidance. Hydrobiologia 653: 191-215.

Davy-Bowker, J., R. Clarke, T. Corbin, H. Vincent, J. Pretty, A. Hawczak, J. Blackburn, J. Murphy, and I. Jones. 2008. River invertebrate classification tool. Sniffer, Edinburgh, Scotland.

Davy-Bowker, J., R. Clarke, R. Johnson, J. Kokes, J. Murphy, and S. Zahrádková. 2006. A comparison of the European Water Framework Directive physical typology and RIVPACS-type models as alternative methods of establishing reference conditions for benthic macroinvertebrates. Hydrobiologia 566: 91-105.

Dickens, C. W. S., and P. M. Graham. 2002. The South African Scoring System (SASS) version 5 rapid bioassessment method for rivers. African Journal of Aquatic Science 27:1-10.

Dixon, C. G. 1956. Geology of southern British Honduras, Belize, British Honduras. Government Printer, Belize City, Belize.

Dolédec, S., and B. Statzner. 2010. Responses of freshwater biota to human disturbances: contribution of J-NABS to developments in ecological integrity assessments. Journal of the North American Benthological Society 29:286-311.

Dudgeon, D. 1982. The life history of Brotia hainanensis (Brot, 1872) (Gastropoda: Prosobranchia: Thiaridae) in a tropical 
forest stream. Zoological Journal of the Linnean Society 76 : 141-154.

Dudgeon, D. 1999. Tropical Asian streams: zoobenthos, ecology and conservation. Hong Kong University Press, Aberdeen, Hong Kong.

Dudgeon, D. 2012. Responses of benthic macroinvertebrate communities to altitude and geology in tributaries of the Sepik River (Papua New Guinea): the influence of taxonomic resolution on the detection of environmental gradients. Freshwater Biology 57:1794-1812.

Dufrêne, M., and P. Legendre. 1997. Species assemblages and indicator species: the need for a flexible asymmetrical approach. Ecological Monographs 67:345-366.

Erman, D., and N. Erman. 1984. The response of stream macroinvertebrates to substrate size and heterogeneity. Hydrobiologia 108:75-82.

Esselman, P. C. 2001. An ecological baseline study of physical habitat, water chemistry and fish assemblages of the Monkey River watershed, Belize. MSc Thesis, University of Georgia, Augusta, Georgia.

Esselman, P. C., M. C. Freeman, and C. M. Pringle. 2006. Fishassemblage variation between geologically defined regions and across a longitudinal gradient in the Monkey River Basin, Belize. Journal of the North American Benthological Society 25:142-156.

Esselman, P. E., J. Meerman, E. Boles, G. Myvett, J. Higgins, A. Warner, T. Fitzhugh, P. Morgan, and R. Frutos. 2005. Belize aquatic ecosystems. $2^{\text {nd }}$ draft. (Available from: http:// biological-diversity.info/aquatic-ecosystems.htm)

Flecker, A. S., and B. Feifarek. 1994. Disturbance and the temporal variability of invertebrate assemblages in two Andean streams. Freshwater Biology 31:131-142.

Goulart, M., and M. Callisto. 2005. Mayfly distribution along a longitudinal gradient in Serra do Cipó, southeastern Brazil. Acta Limnologica Brasiliensia 17:1-13.

Hawkins, C. P., J. R. Olson, and R. A. Hill. 2010. The reference condition: predicting benchmarks for ecological and waterquality assessments. Journal of the North American Benthological Society 29:312-343.

Huryn, A. D., J. B. Wallace, and N. H. Anderson. 2008. Habitat, life history, secondary production and behavioural adaptations of aquatic insects. Pages 55-103 in R. W. Merritt, K. W. Cummins, and M. B. Berg (editors). An introduction to the aquatic insects of North America. $4^{\text {th }}$ edition. Kendall-Hunt Publishing Company, Dubuque, Iowa.

Jackson, D. A. 1995. PROTEST: A PROcrustean randomization TEST of community environment concordance. Ecoscience 2:297-303.

Jacobsen, D. 1998. The macroinvertebrate fauna of Ecuadorian highland streams in the wet and dry season. Archiv für Hydrobiologie 142:53-70.

Jacobsen, D., C. Cressa, J. M. Mathooko, and D. Dudgeon. 2008. Macroinvertebrates: composition, life histories, and production. Pages 66-105 in D. Dudgeon (editor). Tropical stream ecology. Elsevier Academic Press, London, UK.

Jin, H.-S., and G. Ward. 2007. Life history and secondary production of Glossosoma nigrior Banks (Trichoptera: Glossosomatidae) in two Alabama streams with different geology. Hydrobiologia 575:245-258.
Johnson, R. C., M. M. Carreiro, H.-S. Jin, and J. D. Jack. 2012. Within-year temporal variation and life-cycle seasonality affect stream macroinvertebrate community structure and biotic metrics. Ecological Indicators 13:206-214.

Jolliffe, I. 2002. Principal component analysis. Wiley Online Library, New York.

Kaufmann, P. R., P. Levine, E. G. Robison, C. Seeliger, and D. V. Peck. 1999. Quantifying physical habitat in wadeable streams. EPA/620/R-99/003. US Environmental Protection Agency, Washington, DC.

Linke, S., R. H. Norris, D. P. Faith, and D. Stockwell. 2005. ANNA: A new prediction method for bioassessment programs. Freshwater Biology 50:147-158.

McKillop, W. B. 1985. Distribution of aquatic gastropods across the Ordovician dolomite-Precambrian granite contact in southeastern Manitoba, Canada. Canadian Journal of Zoology 63:278-288.

Melo, A. S., and C. G. Froehlich. 2001. Macroinvertebrates in neotropical streams: richness patterns along a catchment and assemblage structure between 2 seasons. Journal of the North American Benthological Society 20:1-16.

Merritt, R. W., K. W. Cummins, and M. B. Berg. 2008. An introduction to the aquatic insects of North America. KendallHunt, Dubuque, Iowa.

Merritt, R. W., and J. B. Wallace. 2009. Aquatic habitats. Pages 38-48 in V. H. Resh and R. T. Cardé (editors). Encyclopedia of insects. Academic Press, Amsterdam, The Netherlands.

MINAE-S (Ministerio de Ambiente y Energía). 2007. Decreto No. 33903. Reglamento para la evaluación y clasificación de la calidad de los cuerpos de agua superficiales. No. 178. La Gaceta Digital, San José, Costa Rica. (Available from: http://www .siagua.org/sites/default/files/documentos/legislacion/33903.pdf)

Ministério do Meio Ambiente. 2012. Resoluções do Conama: resoluções vigentes publicadas entre setembro de 1984 e janeiro de 2012. Ministério do Meio Ambiente, Brasília, Brazil. (Available from: http://www.terrabrasilis.org.br/ecotecadigital/pdf /resolucoes-do-conama-resolucoes-vigentes-publicadas-entre -setembro-de-1984-e-janeiro-de-2012.pdf)

Minshall, G. W. 1984. Aquatic insect-substratum relationships. Pages 358-400 in V. H. Resh and D. M. Rosenberg (editors). The ecology of aquatic insects. Prager Publishers, New York.

Morse, J. C., Y. J. Bae, G. Munkhjargal, N. Sangpradub, K. Tanida, T. S. Vshivkova, B. X. Wang, L. F. Yang, and C. M. Yule. 2007. Freshwater biomonitoring with macroinvertebrates in East Asia. Frontiers in Ecology and the Environment 5:33-42.

Mosher, J. J., and R. H. Findlay. 2011. Direct and indirect influence of parental bedrock on streambed microbial community structure in forested streams. Applied and Environmental Microbiology 77:7681-7688.

Moya, N., R. M. Hughes, E. Domínguez, F.-M. Gibon, E. Goitia, and T. Oberdorff. 2011. Macroinvertebrate-based multimetric predictive models for evaluating the human impact on biotic condition of Bolivian streams. Ecological Indicators 11:840-847.

Munné, A., and N. Prat. 2011. Effects of Mediterranean climate annual variability on stream biological quality assessment using macroinvertebrate communities. Ecological Indicators $11: 651-662$.

Mykrä, H., J. Heino, and T. Muotka. 2004. Variability of lotic macroinvertebrate assemblages and stream habitat charac- 
teristics across hierarchical landscape classifications. Environmental Management 34:341-352.

Natural Resources Conservation Service. 1998. Stream visual assessment protocol. Natural Resources Conservation Service, Washington, DC. (Available from: http://www.nrcs .usda.gov/Internet/FSE_DOCUMENTS/stelprdb1044776.pdf)

Neff, M. R., and D. A. Jackson. 2011. Effects of broad-scale geological changes on patterns in macroinvertebrate assemblages. Journal of the North American Benthological Society 30:459-473.

Newman, R. M. 1991. Herbivory and detritivory on freshwater macrophytes by invertebrates: a review. Journal of the North American Benthological Society 10:89-114.

Nolte, U., M. J. de Oliveira, and E. Stur. 1997. Seasonal, dischargedriven patterns of mayfly assemblages in an intermittent Neotropical stream. Freshwater Biology 37:333-343.

Oliveira, R. B. S., D. F. Baptista, R. Mugnai, C. M. Castro, and R. M. Hughes. 2011. Towards rapid bioassessment of wadeable streams in Brazil: development of the Guapiaçu-Macau Multimetric Index (GMMI) based on benthic macroinvertebrates. Ecological Indicators 11:1584-1593.

Olson, J. R. 2012. The influence of geology and other environmental factors on stream water chemistry and benthic invertebrate assemblages. PhD Thesis, Utah State University, Logan, Utah.

Omernik, J. M. 1995. Ecoregions: a framework for managing ecosystems. George Wright Forum 12:35-50.

Paulson, D. R. 2004. Critical species of Odonata in the Neotropics. International Journal of Odonatology 7:163-188.

Peck, D. V., A. T. Herlihy, B. H. Hill, R. M. Hughes, P. R. Kauffman, D. J. Klemm, J. M. Lazorchak, F. H. McCormick, S. A. Peterson, P. L. Ringold, T. Magee, and M. Cappaert. 2006. Environmental Monitoring and Assessment ProgramSurface Waters Western Pilot Study: field operations manual for wadeable streams. EPA/620/R-06/003. US Environmental Protection Agency, Washington, DC.

Poff, N. L., J. D. Olden, D. M. Pepin, and B. P. Bledsoe. 2006. Placing global stream flow variability in geographic and geomorphic contexts. River Research and Applications 22:149-166.

Rabeni, C., and G. Minshall. 1977. Factors affecting microdistribution of stream benthic insects. Oikos 29:33-43.

Ramírez, A., and C. M. Pringle. 2001. Spatial and temporal patterns of invertebrate drift in streams draining a Neotropical landscape. Freshwater Biology 46:47-62.

Ramírez, A., and C. M. Pringle. 2006. Fast growth and turnover of chironomid assemblages in response to stream phosphorus levels in a tropical lowland landscape. Limnology and Oceanography 51:189-196.

Ramírez, A., C. M. Pringle, and M. Douglas. 2006. Temporal and spatial patterns in stream physicochemistry and insect assemblages in tropical lowland streams. Journal of the North American Benthological Society 25:108-125.

Ramos-Escobedo, M. G., and G. Vázquez. 2001. Major ions, nutrients and primary productivity in volcanic neotropical streams draining rainforest and pasture catchments at Los Tuxtlas, Veracruz, Mexico. Hydrobiologia 445:67-76.

Rios-Touma, B., N. Prat, and A. C. Encalada. 2012. Invertebrate drift and colonization processes in a tropical Andean stream. Aquatic Biology 14:233-246.

Sanchez-Montoya, M. D. M., T. Puntí, M. L. Suarez, M. D. R. Vidal-Abarca, M. Rieradevall, J. M. Poquet, C. ZamoraMuñoz, S. Robles, M. Álvarez, J. Alba-Tercedor, M. Toro, A. M. Pujante, A. Munne, and N. Prat. 2007. Concordance between ecotypes and macroinvertebrate assemblages in Mediterranean streams. Freshwater Biology 52:2240-2255.

Shelley, A. J., L. M. Hernandez, and M. Penn. 2002. A biosystemic revision of the blackflies (Diptera: Simuliidae) of Belize, Central America. Bulletin of the Natural History Museum: Entomology 71:135-271

Snelder, T. H., F. Cattanéo, A. M. Suren, and B. J. F. Biggs. 2004. Is the river environment classification an improved landscape-scale classification of rivers? Journal of the North American Benthological Society 23:580-598.

Springer, M., A. Ramírez and P. Hanson. 2010. Macroinvertebrados de agua dulce de Costa Rica I, San Jose, Costa Rica. Revista de Biologia Tropical 58 (Supplement 4).

Thorp, J. H., and A. P. Covich. 2009. Ecology and classification of North American freshwater invertebrates. Academic Press, San Diego, California.

Townsend, C. R., and A. G. Hildrew. 1994. Species traits in relation to a habitat templet for river systems. Freshwater Biology 31:265-275.

Vannote, R. L., G. W. Minshall, K. W. Cummins, J. R. Sedell, and C. E. Cushing. 1980. River continuum concept. Canadian Journal of Fisheries and Aquatic Sciences 37:130-137.

Van Sickle, J. 2008. An index of compositional dissimilarity between observed and expected assemblages. Journal of the North American Benthological Society 27:227-235.

Vaughn, C. C. 1987. Substratum preference of the caddisfly Helicopsyche borealis (Hagen) (Trichoptera: Helicopsychidae). Hydrobiologia 154:201-205.

Vinson, M. R., and C. P. Hawkins. 1998. Biodiversity of stream insects: variation at local, basin, and regional scales. Annual Review of Entomology 43:271-293.

Webb, B. W., D. M. Hannah, R. D. Moore, L. E. Brown, and F. Nobilis. 2008. Recent advances in stream and river temperature research. Hydrological Processes 22:902-918.

Wright, J. F. 2000. An introduction to RIVPACS. Freshwater Biological Association, Plymouth, UK. 